\title{
Dyke-Davidoff-Masson syndrome: an endocrine perspective
}

\author{
Cristina Dumitrescu', Anda Dumitrascu', Corina Chirita2 ${ }^{2}$ Eugenia Petrova1,3, \\ Nicoleta Dumitru ${ }^{1,3}$, Adina Ghemigian ${ }^{1,3}$, Mara Carsote ${ }^{1,3}$, Dana Terzea ${ }^{1,4}$, Ana Valea $^{5,6}$ \\ 1"C.I. Parhon" National Institute of Endocrinology, Bucharest, Romania \\ ${ }^{2}$ MedicZone Medical Centre, Bucharest, Romania \\ 3"Carol Davila" University of Medicine and Pharmacy, Bucharest, Romania \\ ${ }^{4}$ Oncoteam, Bucharest, Romania \\ ${ }^{5}$ Clinical County Hospital, Cluj-Napoca, Romania \\ 6"Iuliu Hatieganu" University of Medicine and Pharmacy, Cluj-Napoca, Romania
}

\begin{abstract}
Dyke-Davidoff-Masson syndrome (DDMS) represents a severe disease that is caused by brain anomalies of different mechanisms early in life during fetal period or within first years after birth. This is a brief point of view of DDMS through an endocrine perspective. In DDMS, low TSH (thyroid stimulating hormone) hypothyroidism is part of a variable cocktail of endocrine anomalies like pituitary insufficiency that actually seem less relevant opposite to massive neurological damage which marks the clinical picture. Overall, the most spectacular anomaly and the most specific in DMMS is the imaging aspect of the brain hemiatrophy. The syndrome itself, even with a very low prevalence in general population (the level of statistical evidence is case report or series), has a heterogeneous presentation and a large area of clinical combo involving not only neurological field. On the other hand, cerebral hemiatrophy (also a rare neuroimaging finding) may have other causes, either acquired or congenital. Seizures induced by brain damage may be presented long before the imaging recognition of the syndrome is actually done. The endocrine disturbances vary and they may be subtle like central hypothyroidism or life threatening like adrenal crisis due to secondary adrenal insufficiency.

Overall, DDMS represents a complex challenge from severe neurological deterioration to neuro-imagery features centered on the brain hemiatrophy to skin and bone anomalies as well as endocrine disorders which are either deficiency of pituitary hormones or diabetes mellitus and autoimmune thyroiditis. Early recognition is useful for long term prognosis, a multidisciplinary approach is essential. Underlying causes and specific clusters of classification are still running under a large shadow of unknown data.
\end{abstract}

Keywords: Dyke-Davidoff-Masson syndrome, hypothyroidism, cerebral hemiatrophy

\section{INTRODUCTION}

Dyke-Davidoff-Masson syndrome (DDMS) is a severe disease that is caused by brain damage of different mechanisms early in life during fetal period or within first years after birth (1). Cerebral anomalies may be caused in some cases by cerebral vessels congenital damage in addition to skin vascular malformations, bones anomalies at the level of skull and sinuses, face, peripheral skeleton (called Legg-Calve-Perthes-like disease) and even autoimmune conditions like insulin dependent diabetes mellitus and thyroiditis.

\section{OBJECTIVE}

This is a brief point of view starting with a medical image of a prior unpublished DDMS case (respecting the anonymity of the medical data).

\section{MEDICAL IMAGE}

This is the computed tomography (CT) aspect of the brain (Figures 1,2) and pituitary gland (Figures 3,4) of a 19-year old non-smoker male diagnosed with DDMS syndrome soon after birth presenting with left cerebral atrophy which 
suffered a liquid transformation as well as empty sella appearance at imaging scan. In additoion to multiple neurological issues, the patient associates GH (growth hormone), prolactin and TSH (thyroid stimulating hormone) deficiency which were recognized during childhood.
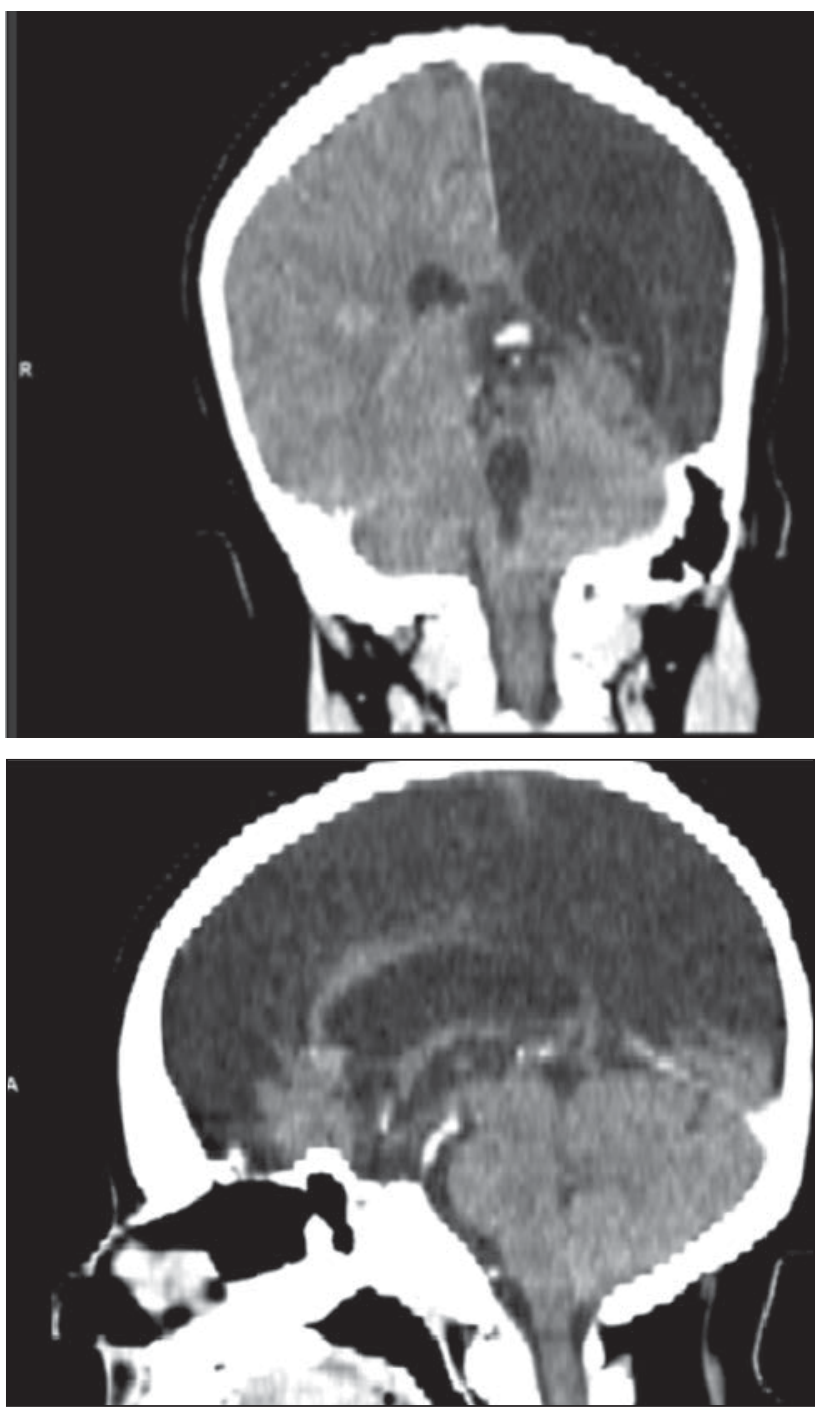

FIGURES 1 and 2. Computed tomography (CT) aspect of the brain
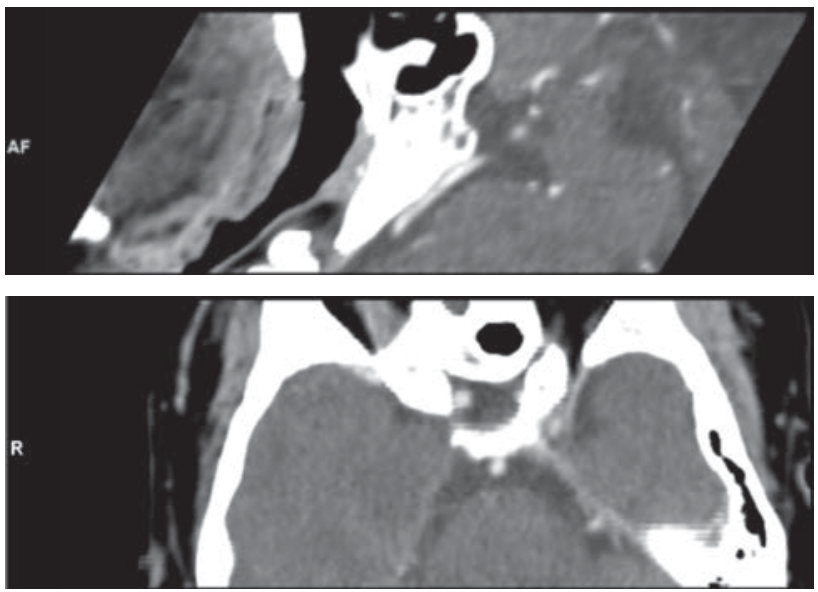

FIGURES 3 and 4. Computed tomography (CT) aspect of the pituitary gland

\section{DISCUSSION}

DDMS- associated hypothyroidism is an atypical one, among various causes like iodine - deficiency related goitre and chronic thyroiditis $(2,3)$. Actually, Hashimoto disease of the thyroid represents the most common cause of thyroid hormones insufficiency in paediatric population, as a single entity or (less frequent) in addition to autoimmune damage of the adrenals etc. $(4,5)$. Central hypothyroidism is found rarer that primary forms and it may be related to genetic causes or to pituitary tumours/masses/neoplasia of secretor or non-secretor pattern, usually of more than 1 centimetre diameter which are rarely detected as incidentaloma and rather as hypothalamic-hypophysis hormones deficiency, including diabetes insipidus, or optic chiasm anomalies etc. (6-8).

In DDMS, low TSH hypothyroidism is part of a variable cocktail of endocrine anomalies that actually seem less relevant opposite to massive neurological damage which marks the clinical picture $(1,9)$. Cerebral anomalies may be caused in some cases by cerebral vessels congenital damage in addition to skin vascular malformations, bones anomalies at the level of skull and sinuses, face, peripheral skeleton (called Legg-Calve-Pertheslike disease) and even autoimmune conditions like insulin dependent diabetes mellitus and thyroiditis (10). Low TSH levels differentiate an autoimmune thyroiditis - associated hypothyroidism to an empty sella-related one (11). Secondary adrenal insufficiency, but not autoimmune Addison disease, was also reported in a limited number of cases which may become life threatening if it is unrecognized $(12,13)$. However, the most frequent endocrine autoimmune DDMS associated conditions remain diabetes and thyroiditis (14).

In this syndrome, endocrine disorders may exceptionally include dwarfism due to GH deficiency which may be, otherwise, caused by other genetic conditions, neonatal trauma, large pituitary masses etc. (15-17). Prolactin anomalies in DDMS may go in both ways: up due to lifelong requirement of neurological medication like against epilepsy crises or down as part of a severe pituitary insufficiency $(1,18)$. Also, a certain correlation with schizoaffective disorders in DDMS have been reported and the specific medication for them may induce a high prolactin level (19). Drug induced hyperprolactinemia in children and youth needs to be differentiated from a prolactinoma, renal failure, severe myxedema, thoracic trauma etc. (20-22).

In addition to neurological, vascular and endocrine disturbances, oral anomalies have been re- 
ported like delayed tooth eruption, teeth hypoplasia and even taurodontism etc. (23). Other endocrine causes of oral anomalies (not necessarily related to neurological syndromes) are presented in gigantism/acromegaly or sever vitamin D deficiency in early childhood years etc. $(24,25)$.

Some cases of DMMS are actually recognized during teenager period of time even symptoms like convulsions are persistent since early years after birth $(26,27)$. The use of neurological medication, long standing uncontrolled hyperprolactinemia, food intake anomalies, low IGF-1 (insulin-like growth factor) impair optimal peak bone mass achievement and eventually bone turnover and bone mass (28-30).

Brain anomalies may be masked by headache especially in cases with late establishment of the DMMS diagnosis during adult life $(31,32)$. Headache in endocrine conditions may be caused in both pediatric and adult population by large pituitary tumors or high blood pressure due to endocrine hyper-production of hypophysis and adrenal tumors like GH or cortisol $(33,34)$.

Overall, the most spectacular anomaly and the most specific in DMMS is the imaging aspect of the brain with hemiatrophy (35). The DMM syndrome itself, even with a very low prevalence in general population (the level of statistical evidence is case report or series), has a heterogeneous presentation and a large area of clinical combo involving not only neurological field (36). On the other

\section{REFERENCES}

1. Benvenga S, Klose M, Vita R, Feldt-Rasmussen U. Less known aspects of central hypothyroidism: Part 1 - Acquired etiologies. J Clin Transl Endocrinol. 2018;14:25-33.

2. Dumitru N, Ghemigian A, Carsote M, Albu SE, Terzea D, Valea A. Thyroid nodules after initial evaluation by primary health care practitioners: an ultrasound pictorial essay. Archives of the Balkan Medical Union. 2016;51(3):434-8.

3. Ghemigian A, Carsote M, Petrova E, Valea A, Dumitru N, Cocolos A. Detection of thyroid nodules by routine ultrasound. Romanian Journal of Medical Practice. 2017;12;4(53):224-9.

4. Albu SE, Carsote M, Terzea D, Ghemigian A, Valea A, Petrova E, Vasiliu C. Thyroid autoimmune disease: between hypothyroidism and hyperthyroidism. Archives of Balkan Medical Union. 2016; 51(4):481-485.

5. Carsote M, Ghemigian A, Terzea D, Gheorghisan-Galateanu AA, Valea A. Cystic adrenal lesions: focus on pediatric population (a review). Clujul Medical. 2017;90(1):5-12.

6. Valea A, Carsote M, Ghervan C, Georgescu C. Glycemic profile in patients with acromegaly treated with somatostatin analogue. Journal of Medicine and Life 2015;8(Spec Issue):82-6.

7. Valea A, Ghervan C, Carsote M, Morar A, lacob I, Tomesc F, Pop DD, Georgescu C. Effects of combination therapy: somatostatin analogues and dopamine agonists on GH and IGF1 levels in acromegaly. Clujul Medical 2015;88(3):310-17. hand, cerebral hemiatrophy (also a rare neuroimaging finding) may have other causes, either acquired or congenital $(37,38)$. Seizures induced by brain damage may be presented long before the imaging recognition of the syndrome is actually done $(39,40)$.

\section{CONCLUSIONS}

DDMS represents a complex challenge from severe neurological damage to neuro-imagery features centered on the brain hemiatrophy to skin and bone anomalies and endocrine disorders in some cases like deficiency of pituitary hormones. Early recognition is useful for long term prognosis, a multidisciplinary approach is essential. Underlying causes and specific clusters of classification are still running under a large shadow of unknown data.

\section{Disclaimer}

The medical images were not previously published. However, the case data were partially introduced at ENDOPED International Congress 2020 as poster presentation and then selected as oral presentation. The abstract was published as the following citation: Dumitrascu A, Dumitrescu C, Valea A, Carsote M. Central Hypothroidism: The Endocrine "Memory" for Dyke-Davidoff-Masson Syndrome. CEACR (Central European Annals of Clinical Research). 2020;2(2):16.

Conflict of interest: none declared Financial support: none declared

8. Gheorghisan-Galateanu AA, Carsote C, Valea A. Incidentaloma: from general practice to specific endocrine frame. JPMA. The Journal of the Pakistan Medical Association. 2017; 67(6):917-922.

9. Benvenga S, Klose M, Vita R, Feldt-Rasmussen U. Less known aspects of central hypothyroidism: Part 2 - Congenital etiologies. J Clin Transl Endocrinol. 2018;14:5-11.

10. Ruggieri M, Milone P, Pavone P, Falsaperla R, Polizzi A, Caltabiano R, Fichera M, Gabriele AL, Distefano A, De Pasquale R, Salpietro V, Micali G, Pavone L. Nevus vascularis mixtus (cutaneous vascular twin nevi) associated with intracranial vascular malformation of the Dyke-Davidoff-Masson type in two patients. Am J Med Genet A. 2012;158A(11):2870-80.

11. Kim JW, Kim ES, Kim W, Kim YD, Mo EY, Moon SD, Han JH. A case of Dyke-Davidoff-Masson syndrome associated with central hypothyroidism and secondary adrenal insufficiency. Hormones (Athens). 2013;12(3):461-5.

12. Valea A, Albu SE, Petrescu R, Carsote M. Chronic thyroiditis and differentiated thyroid cancer: from overlapping high prevalence to a shift on multifocal intra-thyroid papillary thyroid carcinoma. Journal of Surgical Sciences. 2017;4(1):38-45.

13. Valea A, Carsote M. Diagnosis of Addison's disease in a patient with newly diagnosed renal insufficiency having a context of autoimmune poly-endocrine syndrome. Acta Medica Transilvanica. 2016; 21(4):45-47. 
14. Ruggieri M, Polizzi A, Strano S, Schepis C, Morano M, Belfiore G, Palmucci S, Foti PV, Pirrone C, Sofia V, David E, Salpietro V, Mankad K, Milone P. Mixed vascular nevus syndrome: a report of four new cases and a literature review. Quant Imaging Med Surg. 2016; 6(5):515-524.

15. Carsote M, Albu SE, Ghemigian A, Georgescu C, Valea A. Surgical approach in pituitary tumours: the role of endocrine profile. Journal of Surgical Sciences. 2015;2(4):176-182.

16. Güven H, Aytaç E, Comoğlu SS. Dyke-Davidoff-Masson syndrome: a case with additional brain abnormalities. Acta Neurol Belg. 2014; 114(3):247-9.

17. Bagazgoitia L, García-Peñas JJ, Duat-Rodríguez A, HernándezMartín A, Torrelo A. Facial capillary malformation and Dyke-DavidoffMasson syndrome. Pediatr Neurol. 2010;43(3):202-4.

18. Dilber B, Sahin S, Eyüboğlu I, Kamaşak T, Acar Arslan E, Durgut BD, Cansu A. Two Different Manifestations of Neonatal Vascular Injury: Dyke-Davidoff-Masson Syndrome and Crossed Cerebellar Atrophy. J Stroke Cerebrovasc Dis. 2020;29(3):104600.

19. Hamza N, Hdiji O, Haj Kacem H, Farhat N, Sakka S, Dammak M, Mhiri C. Dyke Davidoff Masson syndrome a rare cause of schizoaffective disorder: A case report and review of the literature. Encephale. 2019;45(3):274-275.

20. Ghemigian A, Carsote M, Ghervan C, Dumitrascu A, Albu SE, Georgescu CE, Valea A. Long-term follow-up after transcranial hypophysectomy in macroprolactinomas. Journal of Surgical Sciences. 2016;3(1):44-50.

21. Poiana C, Chirita C, Carsote M, Hortopan D, Goldstein A. Galactocele and prolactinoma - A pathogenic association? Maturitas. 2009;62(1):98-102.

22. Ghemigian A, Carsote M, Dumitru N, Valea A. Adult male with bicytopenia: is this the first manifestation of a prolactinoma? Archives of the Balkan Medical Union. 2016;51(3):429-433.

23. Kalaskar R, Kalaskar AR. Classical oral manifestations of DykeDavidoff-Masson syndrome: a case report with review of the literature. J Korean Assoc Oral Maxillofac Surg. 2018;44(4):198-203.

24. Carsote M, Ghemigian A, Ghervan C, Valea A. Acromegaly: focus on facial, oral, and dental anomalies. Medicine in evolution. 2016; 22(2):241-247.

25. Ghemigian A, Cocolos A, Dumitru N, Petrova E, Valea A, Carsote M. Vitamin $D$ during pregnancy: a strong player in a battle for two. Romanian Medical Journal. 2018;65(2):89-91.

26. Li Y, Zhang T, Li B, Li J, Wang L, Jiang Z. A potential cause of adolescent onset Dyke-Davidoff-Masson syndrome: A case report. Medicine (Baltimore). 2019;98(51):e18075.
27. Diestro JDB, Dorotan MKC, Camacho AC, Perez-Gosiengfiao KT, Cabral-Lim LI. Clinical spectrum of Dyke-Davidoff-Masson syndrome in the adult: an atypical presentation and review of literature. BMJ Case Rep. 2018 Jul 3;2018:bcr2018224170.

28. Carsote M, Valea A. Insights of peak bone mass. Acta Medica Transilvanica. 2016;21(2):82-85.

29. Radu L, Carsote M, Gheorghisan-Galateanu AA, Preda SA, Calborean V, Stanescu R, Gheorman V, Albulescu DM. Blood Parathyrin and Mineral Metabolism Dynamics A clinical analyze. Revista de Chimie. 2018;69(10):2754-8.

30. Carsote M, Radoi V, Geleriu A, Mihai A, Ferechide S, Opris D, Paun $\mathrm{D}$, Poiana $\mathrm{C}$. The serotonin and the bone assessment. Journal of Medicine and Life. 2013;6(2):151-155.

31. Aldhaleei WA, Bhagavathula AS, Alshehhi F. Dyke-Davidoff-Masson syndrome presenting as recurrent chronic headache in the late adult life. Brain Circ. 2020;6(2):123-125.

32. Shahid R. An unusual presentation of Dyke-Davidoff Masson syndrome. Neurosciences (Riyadh). 2018;23(3):254-257.

33. Trifanescu R, Carsote M, Caragheorgheopol, Hortopan D, Dumitrascu A, Dobrescu R, Poiana C. Screening for Secondary Endocrine Hypertension in Young Patients. Maedica - a Journal of Clinical Medicine 2013;8(2):108-115.

34. Valea A, Carsote M, Ghemigian A, Dumitrache C. Pituitary macroadenoma and thyroid autoimmunity: cross-sectional observations in adult population. Current Health Sciences Journal. 2016;42(S5):50-53.

35. Ayele BA, Zewde YZ. Dyke-Davidoff-Masson syndrome - A Rare Cause of Cerebral Hemiatrophy in a 17-Years-Old Ethiopian Patient: A Case Report. Ethiop J Health Sci. 2019;29(2):287-290.

36. Sharawat IK, Suthar R, Sankhyan N. Dyke-Dav idoff-Masson syndrome: unusual cause of hemiplegic cerebral palsy. BMJ Case Rep. 2019;12(4):e229862

37. Tan AP, Wong YLJ, Lin BJ, Yong HRC, Mankad K. Clinico-radiological approach to cerebral hemiatrophy. Childs Nerv Syst. 2018; 34(12):2377-2390.

38. Durcan R, Smyth S, Bolster F. Teaching Neurolmages: DykeDavidoff-Masson syndrome. Neurology. 2018;90(23):e2097-e2098.

39. Abdul Rashid AM, Md Noh MSF. Dyke-Davidoff-Masson syndrome: a case report. BMC Neurol. 2018;18(1):76.

40. Ayas ZÖ, Asil K, Öcal R. The clinico-radiological spectrum of Dyke-Davidoff-Masson syndrome in adults. Neurol Sci. 2017; 38(10):1823-1828. 